2015 Global Fashion Management Conference at Florence Proceedings: 783-787 (June 2015) http://dx.doi.org/10.15444/GFMC2015.05.05.03

\title{
PRACTICES FOR ENVIRONMENTAL SUSTAINABILITY IN THE ITALIAN FASHION CLOTHING AND LEATHER SECTORS: OUTCOMES OF AN EMPIRICAL RESEARCH
}

\author{
Virginia Fani, University of Florence, Italy ${ }^{1)}$ \\ Romeo Bandinelli, University of Florence, Italy ${ }^{2)}$ \\ Barbara Resta, University of Bergamo, Italy ${ }^{3}$ ) \\ Stefano Dotti, University of Bergamo, Italy ${ }^{4)}$ \\ Rinaldo Rinaldi, University of Florence, Italy ${ }^{5)}$
}

\begin{abstract}
The fashion supply chain, even if represents one of the most important economies of the European industry, is one of the most polluting industries in the world, being a huge consumer of water, electricity and chemicals, and discharging massive quantities of wastes to land. Despite this fact, only few contributions have offered an analysis of the practices adopted by fashion companies to reduce its environmental impact. This paper present an empirical study on the sustainability practices adoption of Italian companies in the fashion Clothing, Leather industries. The research has been conducted through an online survey submitted to a sample of 192 Italian companies, having respectively the 14 and 15 ATECO 2007 code in the AIDA database, with a response rate of $13 \%$.

The results have been analyzed through the statistical software SPSS, in order to conduct a cluster analysis and 6 different clusters have been identified.

Companies belong to cluster 1 do not apply any sustainability practices, even if they are coherent with what they declare on their website. Companies of cluster 2 adopt some practices, but sustainability is not integrated into their culture. Cluster 3 is composed by companies that declare a high interest to the environment, mainly for marketing reason. This way, companies of this group represent the ones more misaligned and not consistent from the practices declared on their website and the one really implemented. Cluster 5 is composed by companies endorsing environmental sustainability as a part of the company values and a high level of practices implemented is reported. Last, companies belonging to Cluster 6 have the environmental sustainability as a strategic objective and implements sustainability practices in a consistent and coordinated way.
\end{abstract}

Keywords: environmental sustainability, textile clothing and leather (TCL) sectors, practices, empirical analysis, Italy.

\footnotetext{
1) virginia.fani@unifi.it

2) romeo.bandinelli@unifi.it

3) barbara.resta@unibg.it

4) stefano.dotti@unibg.it

5) rinaldo.rinaldi@unifi.it
} 


\section{INTRODUCTION}

Fashion Clothing and Leather sectors, together with the Textile one, compose the socalled TCL industry, which represents one of the most important economies of the European industry. In 2011, the European TCL sectors accounted for over 2.5 million direct jobs in 230,000 businesses, representing $4 \%$ of total production, $7 \%$ of jobs in European manufacturing, and generating a turnover of more than 210 billion Euros (ESC, 2012). Leather manufacturing (Eurostat, 2013a; Eurostat, 2013b; Eurostat 2013c) generates the $22 \%$ of the value added of the sector, whilst Clothing one generates the $37 \%$. Italy is the principal textiles, clothing and leather manufacturing Member State, generating 18.7 billion Euros of value added, which is the equivalent of more than one third (35.2\%) of EU-27 value added in these sectors (Eurostat, 2013a; Eurostat, 2013b; Eurostat 2013c).

Despite the importance of these industries for the Italian and European economy, sustainability aspects seem to be still not strategic. Several authors highlight the substantially negative environmental "footprint" of the TLC global supply chain (Allwood et al., 2006; COTANCE, 2012, DEFRA, 2008; Dickson et al., 2009; Fletcher, 2008; Gardetti and Torres, 2013; Gwilt and Rissanen, 2011; Slater, 2003).

At the same time, the EU has expressed a strong interest in shaping how the environmental sustainability concept is understood in global policy terms (Backer, 2000). Several directives, relating to waste management, industrial emissions and chemicals use have been published. Some examples are the Integrated Pollution Prevention and Control (IPPC), Emission Trading System (ETS), Regulation on Registration, Evaluation, Authorisation and Restriction of Chemicals (REACH) and the Water Framework Directive 2000/60/EC.

As a result of this dichotomy, companies' attitude regarding sustainability practices adoptions is very diversified and heterogeneous: while many companies commit to sustainability, few put their commitment into actions, and even fewer communicate their actions and results (Deloitte, 2013).

Last, the literature offers few comprehensive and structured contributions of the different practices that have been employed in the TCL sectors (De Brito et al., 2008) (Chi, 2011) (Caniato et al. 2012).

Thus, the aim of this paper is to contribute to enrich this research field, mapping and analyzing through an empirical research the practices implemented by companies operating in the Italian Clothing and Leather sectors, as the principal European Member State in this industry.

\section{RESEARCH METHODOLOGY}

The analyzed sample is composed by a subset of companies operating in the Clothing and Leather industries having respectively the 14 and 15 ATECO 2007 code in the AIDA database. AIDA, which Italian translation is "Italian company information and business intelligence", is a database containing financial, accounting and commercial information on over 500,000 companies that operate in Italy. The ATECO 2007 is a well-known industry classification of economic activity, adopted by the Italian national institute of statistics (ISTAT). 
From the total amount companies having 14 and 15 ATECO 2007 code, the present study investigates the 192 ones that have explicitly declared the adoption of almost one sustainability practice on their website.

An online survey has been distributed to all the companies, with a response rate of $13 \%$. The questionnaire is structured into 4 sections. Section 1 is related to company's and respondent's general information. Section 2 investigates the sustainable strategy. Section 3 go into details on the adopted sustainable practices, organized in six category (i.e. Products and Services, Supply Chain Management, Production Process, Culture, Governance, Others), according to Resta et al. (2014). Section 4 analyzes the economic impacts of sustainability on the business.

Collected data were analyzed through the statistical software SPSS, in order to conduct a cluster analysis able to highlight several companies sustainability profile. The expected result is that some groups of companies invest more in similar kind of sustainable practices, relating to context variables such as their sustainable strategy and dimension. Cluster analysis is a patterns discovering procedure for identify homogeneous groups of objects, named cluster, characterized by giving similar answers (Cooksey, 2007). Most common methods diffused in literature are hierarchical clustering methods and partitioning methods (such as K-means). In this study, the hierarchical clustering is preferred and the number of extracted clusters is defined applying the Ward's minimum variance method.

\section{MAIN RESULTS}

As result of the implementation of cluster analysis to the collected data sample, six clusters have been identified (Figure 1).

Cluster 1 groups four companies characterized by a declared low commitment towards sustainability. Companies belonging to this cluster are small or medium enterprises not interested in sustainability. The only practices implemented by the companies are related to energy reduction, cost saving and logistic optimization.

In Cluster 2 (two firms), sustainability issues are taken into account and some practices are adopted, but the sustainability is not included in companies' mission and strategy. For instance, the implemented practices deal with the increase of operational efficiency. The economic returns highlighted by the companies of this cluster are a more efficient use of resources, cost reduction, but also a major customer retention, better access to new markets and an increase of the value of the brand.

Cluster 3 collects six companies that declare high efforts towards environmental issues even if they often do not put them into practice. Companies of this group belong to the supply chain of the high-level fashion industry and, among the clusters, represent the ones more misaligned and not consistent from the practices declared on their website and the one really implemented.

In Cluster 4 (three firms), sustainability practices are mainly implemented in order to prevent reputational damage. Public pressure, especially from media, is one of the main drivers that push company towards integrating these issues into its strategy and mission. 
The two companies characterizing Cluster 5 include sustainability into their strategy because of it is part of owners and employees personal values. In this cluster, the most interesting aspect is that the adoption of sustainability practices is carried out with the involvement of customers, local communities and associations.

The last cluster (i.e. Cluster 6) is composed by eight companies. Product differentiation appears to be the source of competitive advantage given by sustainability and stakeholders affected by this policy are the customers, suppliers and employees.

\section{CONCLUSIONS AND IMPLICATIONS}

Even if the size and the nature of the sample and the low response rate makes impossible to generalize the evidence of the study, some empirical evidences can be deducted from this research.

A first evidence is that there are not Italian big companies in the Cluster 3 . The only big companies that implement sustainability practices are international firms with a productive center located in Italy. Moreover, there is not particular misalignment (except for Cluster 5) from what the companies declare on their website and what they really implement. Often the number of practices really adopted is more than the ones declared on the website. The reason of this results can be explained by the fact that, once a practice is explicitly declared, customers and other stakeholders expect its adoption for every time of products and consequently for any time of raw materials or processes.

The last result that can be derived from this research is the alignment between the adoption of sustainability practices and the companies' strategy. Firms focused on cost leadership adopt very few sustainability practices, and the only ones adopted are related to energy reduction and cost savings. On the other hand, companies which strategy is focused on brand loyalty through an environmental sustainability are the ones that implemented the major number of practices.

\section{REFERENCES}

Allwood, J.M., Laursen, S.E., Malvido de Rodriguez, C.M., and Bocken, N.M.P. (2006), Well dressed? The present and future sustainability of clothing and textiles in the United Kingdom, Cambridge: Institute for Manufacturing, University of Cambridge. Available from: www.ifm.eng. cam.ac.uk.

Baker, S. (2000). "The EU: Integration, Competition and Growth and Sustainability", W. Lafferty, \& J. Meadowcroft, Eds.Implementing Sustainable Development, Oxford: Oxford University Press.

Caniato, F., Caridi, M., Crippa, L., and Moretto, A.. (2012),"Environmental sustainability in fashion supply chains: an exploratory case based research. International",Journal of Production Economics, Vol. 135, pp. 659-670.

Chi T. (2011),"Building a sustainable supply chain: An analysis of corporate social responsibility (CSR) practices in the Chinese textile and apparel industry", Journal of the Textile Institute, Vol. 102, pp. 837-848.

Cooksey, R.W., 2007. Illustrating statistical procedures: For business, behavioural \& 
social science research, Prahan, Victoria: Tilde University Press.

COTANCE (2012),Social and Environmental Report- the European leather industry, Available from: http://cotance.com/socialreporting/european-reporting/europeanser.html.

De Brito, M., Carbone, V., andBlanquart, C. (2008), “Towards a sustainable fashion retail supply chain in Europe: organisation and performance",International Journal of Production Economics, Vol. 114 (No. 2), pp. 534-553.

DEFRA (UK Department for Environment, Food and Rural Affairs) (2008),Sustainable Clothing Roadmap Briefing Note December 2007: Sustainability Impacts of Clothing and Current Interventions, London: DEFRA.

Deloitte (2013), Fashioning Sustainability 2013, Copenhagen: Deloitte StatsautoriteretRevisionspartnerseleskab.

Eurostat (2013a),Manufacture of textiles statistics - NACE Rev. 2 - Statistics Explained, Available

from: http://epp.eurostat.ec.europa.eu/statistics_explained/index.php/Manufacture_of_text iles_statistics_-_NACE_Rev._2.

Eurostat (2013b), Manufacture of wearing apparel statistics - NACE Rev. 2 - Statistics Explained, Available from: http://epp.eurostat.ec.europa.eu/statistics_explained/index.php/Manufacture_of_wea ring_apparel_statistics_-_NACE_Rev._2

Eurostat (2013c), Manufacture of leather and related products statistics - NACE Rev. 2 Statistics Explained, Available from: http://epp.eurostat.ec.europa.eu/statistics_explained/index.php/Manufacture_of_leat her_and_related_products_statistics_-_NACE_Rev._2

Resta B., Stefano D., Pinto R., Bandinelli R., Rinaldi R., Ciarapica F. E., (2014), "Practices for Environmental Sustainability in the Textile, Clothing and Leather Sectors: The Italian Case", International Journal of Operations and Quantitative Management, Vol. 20(No. 3), pp. 101-133

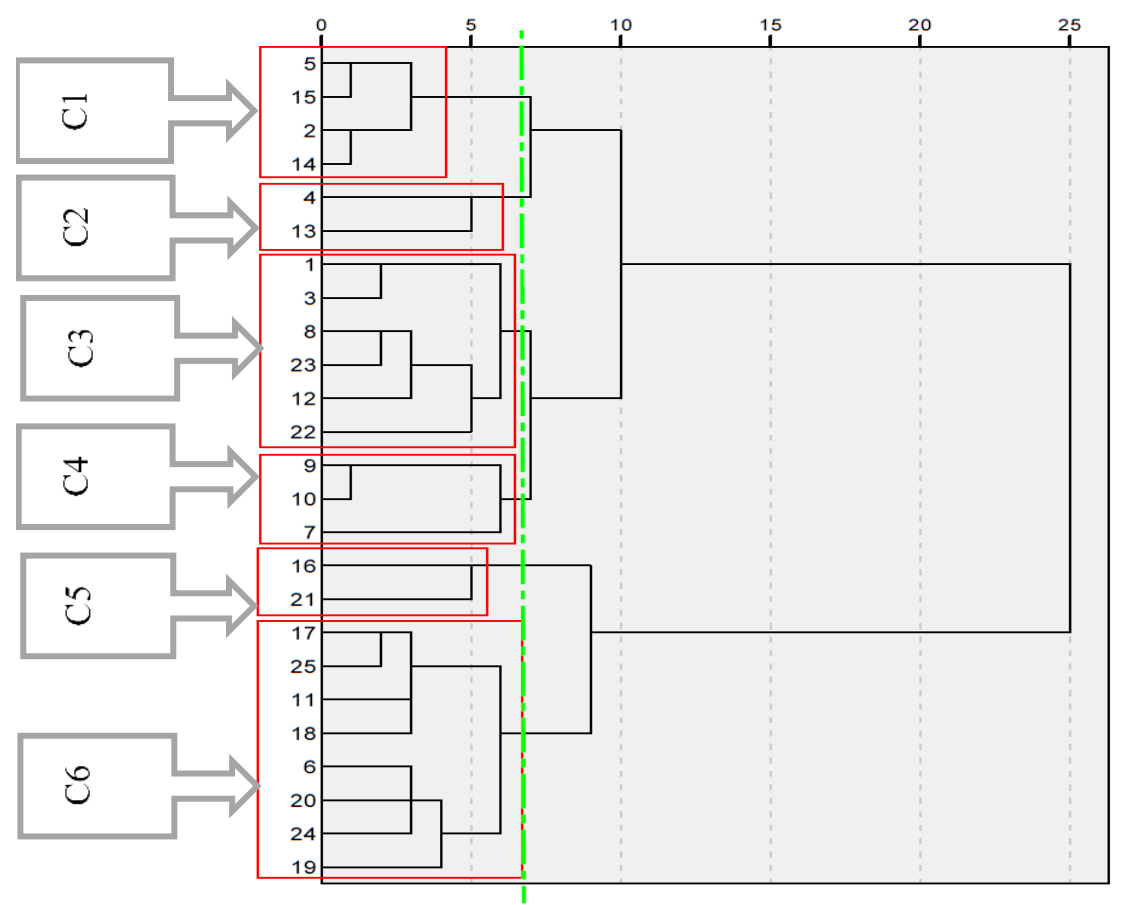

Figure 1 - Dendrogram using Ward Linkage 